\begin{abstract}
CHegeo
International Journal of Environment and Geoinformatics (IJEGEO) is an international, multidisciplinary, peer reviewed, open access journal.
\end{abstract}

\title{
Coastline Difference Measurement (CDM) Method
}

\section{Osman İsa ÇELİK, Cem GAZİŏ́LU}

\author{
Chief in Editor \\ Prof. Dr. Cem Gazioğlu \\ Co-Editors \\ Prof. Dr. Dursun Zafer Şeker, Prof. Dr. Şinasi Kaya, \\ Prof. Dr. Ayşegül Tanık and Assist. Prof. Dr. Volkan Demir
}

Editorial Committee (April 2020)

Assos. Prof. Dr. Abdullah Aksu (TR), Assit. Prof. Dr. Uğur Algancı (TR), Prof. Dr. Bedri Alpar (TR), Prof. Dr. Lale Balas (TR), Prof. Dr. Levent Bat (TR), Prof. Dr. Paul Bates (UK), İrşad Bayırhan (TR), Prof. Dr. Bülent Bayram (TR), Prof. Dr. Luis M. Botana (ES), Prof. Dr. Nuray Çağlar (TR), Prof. Dr. Sukanta Dash (IN), Dr. Soofia T. Elias (UK), Prof. Dr. A. Evren Erginal (TR), Assoc. Prof. Dr. Cüneyt Erenoğlu (TR), Dr. Dieter Fritsch (DE), Assos. Prof. Dr. Çiğdem Göksel (TR), Prof.Dr. Lena Halounova (CZ), Prof. Dr. Manik Kalubarme (IN), Dr. Hakan Kaya (TR), Assist. Prof. Dr. Serkan Kükrer (TR), Assoc. Prof. Dr. Maged Marghany (MY), Prof. Dr. Michael Meadows (ZA), Prof. Dr. Nebiye Musaoğlu (TR), Prof. Dr. Erhan Mutlu (TR), Prof. Dr. Masafumi Nakagawa (JP), Prof. Dr. Hasan Özdemir (TR), Prof. Dr. Chryssy Potsiou (GR), Prof. Dr. Erol Sarı (TR), Prof. Dr. Maria Paradiso (IT), Prof. Dr. Petros Patias (GR), Prof. Dr. Elif Sertel (TR), Prof. Dr. Nüket Sivri (TR), Prof. Dr. Füsun Balık Şanlı (TR), Prof. Dr. Uğur Şanlı (TR), Duygu Ülker (TR), Assoc. Prof. Dr. Oral Yağcı (TR), Prof. Dr. Seyfettin Taş (TR), Assoc. Prof. Dr. Ömer Suat Taşkın (US), Dr. İnese Varna (LV), Dr. Petra Visser (NL), Prof. Dr. Selma Ünlü (TR), Assoc. Prof. Dr. İ. Noyan Yilmaz (AU), Prof. Dr. Murat Yakar (TR), Assit. Prof. Dr. Sibel Zeki (TR)

Abstracting and Indexing: TR DIZIN, DOAJ, Index Copernicus, OAJI, Scientific Indexing Services, International Scientific Indexing, Journal Factor, Google Scholar, Ulrich's Periodicals Directory, WorldCat, DRJI, ResearchBib, SOBIAD 


\title{
Coastline Difference Measurement (CDM) Method
}

\author{
Osman İsa Çelik ${ }^{1, *}$ (iD), Cem Gazioğlu ${ }^{1,2}$ iD \\ ${ }^{1}$ Istanbul University, Institute of Marine Sciences and Management, Department of Marine Environment, 34134 Vefa Fatih ISTANBUL-TR \\ ${ }^{2}$ Istanbul University, Faculty of Architecture, Department of Architecture, 34116 Süleymaniye, ISTANBUL-TR \\ * Corresponding author: \\ E-mail: isa.celk@gmail.com \\ Received 20 Feb 2020 \\ Accepted 26 March 2020
}

How to cite: Çelik \& Gazioğlu (2020). Coastline Difference Measurement (CDM) Method, International Journal of Environment and Geoinformatics (IJEGEO), 7(1): 01-05. DOI: 10.30897/ijegeo.706792

\begin{abstract}
Coastline Difference Measurement (CDM) Method is designed to provide a fast and practical way to obtain distance differences between 2 taut zonal coastlines. Comparison purposes could be considered as change detection to monitoring coastal zones or obtaining accuracies while studying coastline extraction methods. In this study CDM method is explained over a coastline extraction case. In this example case, CDM method is used to measure accuracy of the estimated coastline via Extra Trees (ET) machine learning model. Main advantages and limitations of the methods are explained.
\end{abstract}

Keywords: Coastline Comparison, Change Detection, Coastline Extraction

\section{Introduction}

Coastal areas have emerged to be the most important and dynamic regions, worldwide. They are unique areas on earth because they are the connection between water body and land (Paravolidakis et al., 2018). Coastline is the boundary of the land and ocean masses, and knowledge of the coastline is the basis for measuring and characterizing the resources and environment of the land and ocean (Zhang, et al., 2013). The coastline refers to the intersection where the sea and the land meet, in the simplest terms (Gazioğlu et al., 1997; Kaya, 2010; Simav et al., 2013). Coastline detection is an actual multifarious subject, primarily the improbability of classifying a clear totally accepted description of what a coastline is, furthermore defining a method of monitoring coastline behaviors for a certain period of time (Kavzoğlu \& Cölkesen, 2009). The boundaries in defining the coastal strip with conventional techniques and approaches may be limited to human perception and predictions. However, the fact that the automated systems are being used at a higher rate every day reveals new application requirements in this regard. In general, conventional approaches to coastal line extraction can offer an automated coastline extraction methodology based on region segmentations and image processing techniques for edge detection (Yu et al., 2012).

Irregular and variable geometrical aspects of coastlines could cause uncertainties while comparing spatial differences in area of interests. Comparison purposes could be considered as change detection to monitoring coastal zones (Nassar et al., 2019; Yulianto et al., 2019) or obtaining accuracies while studying coastline extraction methods (Wicaksono et al., 2019; Zollini et al., 2020). While measuring differentiation from a point in the reference coastline, simple point-to-point measuring results could vary according to measurement direction. This direction consists of user-defined directionality along the reference coastline. In that manner, measurement results could vary according to user's datum direction choice. Another problem in this measurement way is caused by strong and frequent directional changes along most of the coastlines. This problem makes one datum direction useless at the most of the cases and forces researchers to create multiple datum directions. As the results of these user dependencies, time loss and different measurements could occur.

Coastline Difference Measurement (CDM) Method is designed to provide a fast and practical way to obtain distance differences between coastlines. Main motivations of this method are decreasing time of preprocessing and providing repeatable results from multiple users while measuring differentiations from reference coastlines. In this study CDM method formulation is explained over a coastline extraction case. In the example case, CDM method is used to measure accuracy of the estimated coastline via Extra Trees (ET) machine learning model.

\section{Material}

For the example case, coastline is provided from a Sentinel-2A Multi-Spectral image (MSI) with 10-m spectral resolutions (Fig. 1a). Area of interest is cropped from image as 300x300 pixels dimensions (Fig. 1b).

Reference coastline is extracted by hand using Global Mapper software (v20.0) produced by Blue Marble Geographics Company (Fig. 2a). To generating estimated coastline, (Fig. 2b) Extra Trees model from the "Scikit-Learn" module is used. 
Scikit-learn is a module for Python programming language that integrates a wide range of modern machine learning algorithms for mid-range supervised and

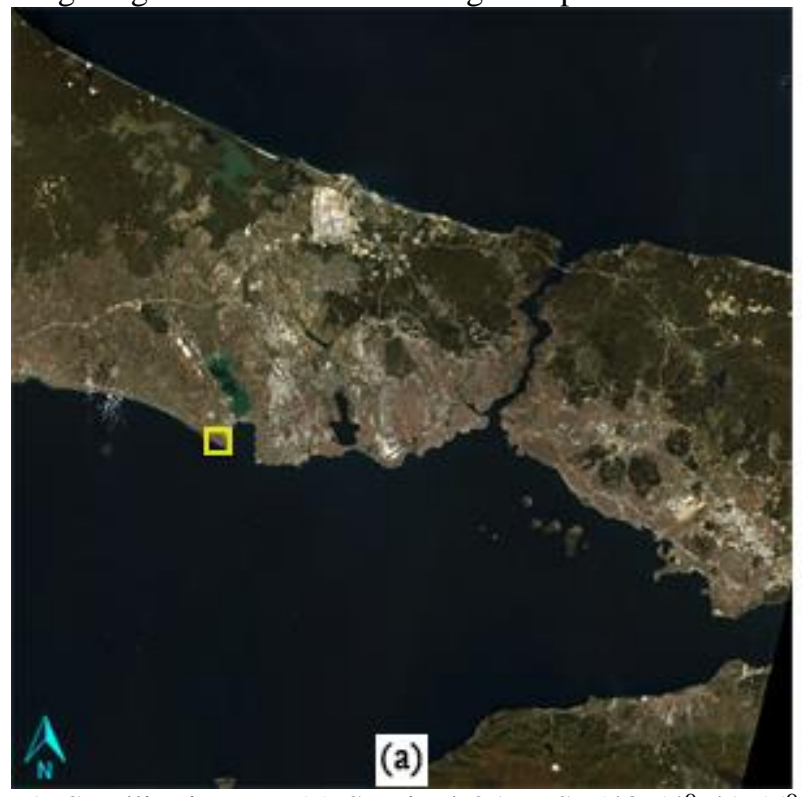

unsupervised problems (Pedregosa et al., 2011; Buitinck et al., 2013). Python programming language (Python, 2020) is also used to apply CDM formulations over the example case.

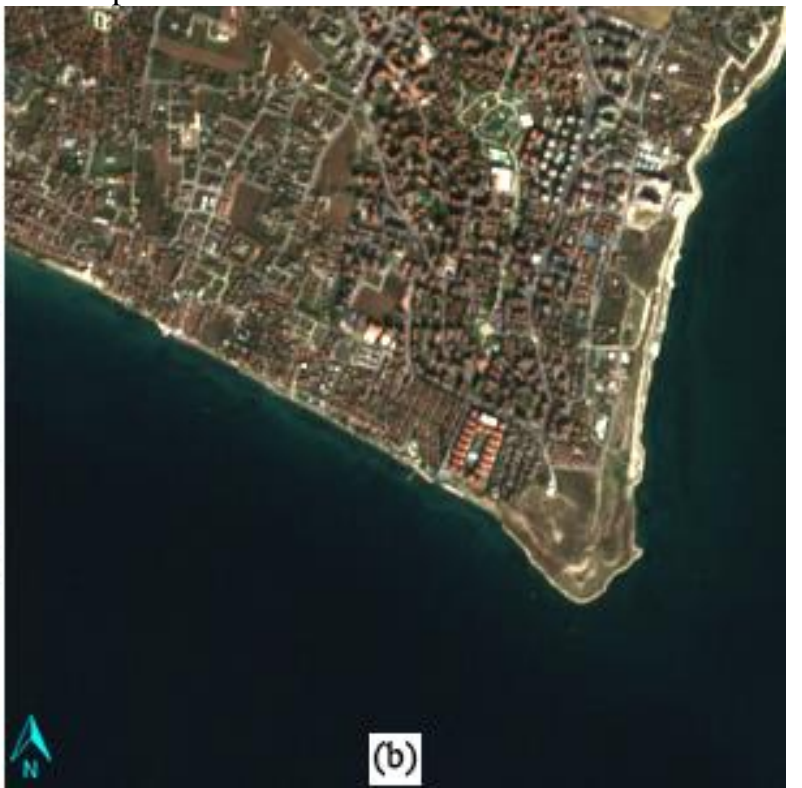

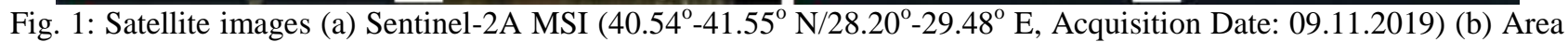
of Interest $\left(40.98^{\circ}-41.01^{\circ} \mathrm{N} / 28.52^{\circ}-29.55^{\circ} \mathrm{E}\right)$
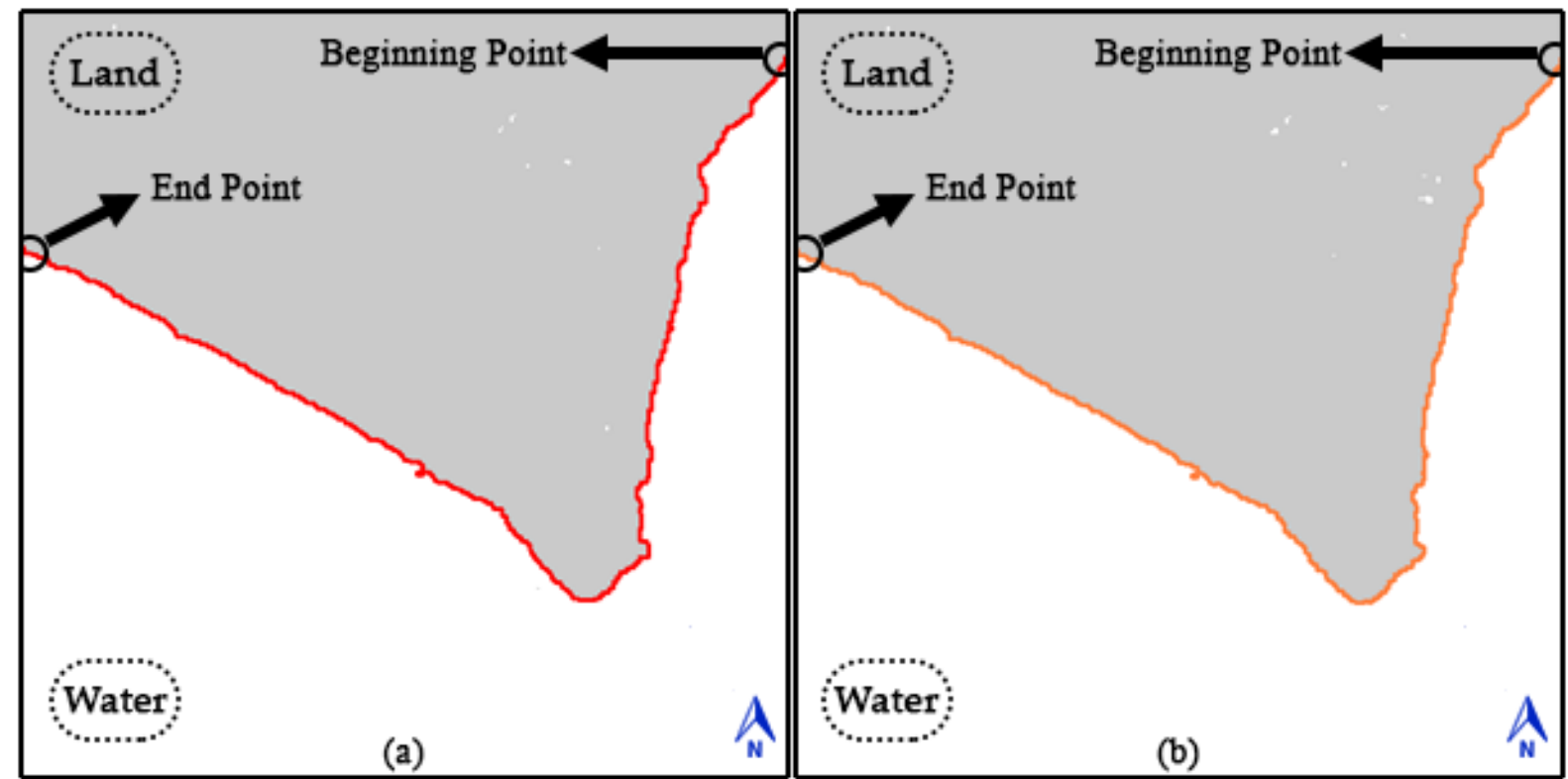

Fig. 2 Compared coastlines (a) Rectified reference coastline (b) Estimated coastline

\section{Method}

Coastline Difference Measurement method starts by finding intersections between reference coastline and differential coastline. Areas which are include deviations from the reference coastline among the intersection points identified as differential parts (Fig. 3). The area (A) between the reference coastline and the differential coastline in the differential parts is calculated. If reference coastline and differential coastline does not share same start point or end point area calculation reveals an error. To preventing the error in such cases, differential coastline is accepted starts and ends by the same points with reference coastline with 2 additional points. 


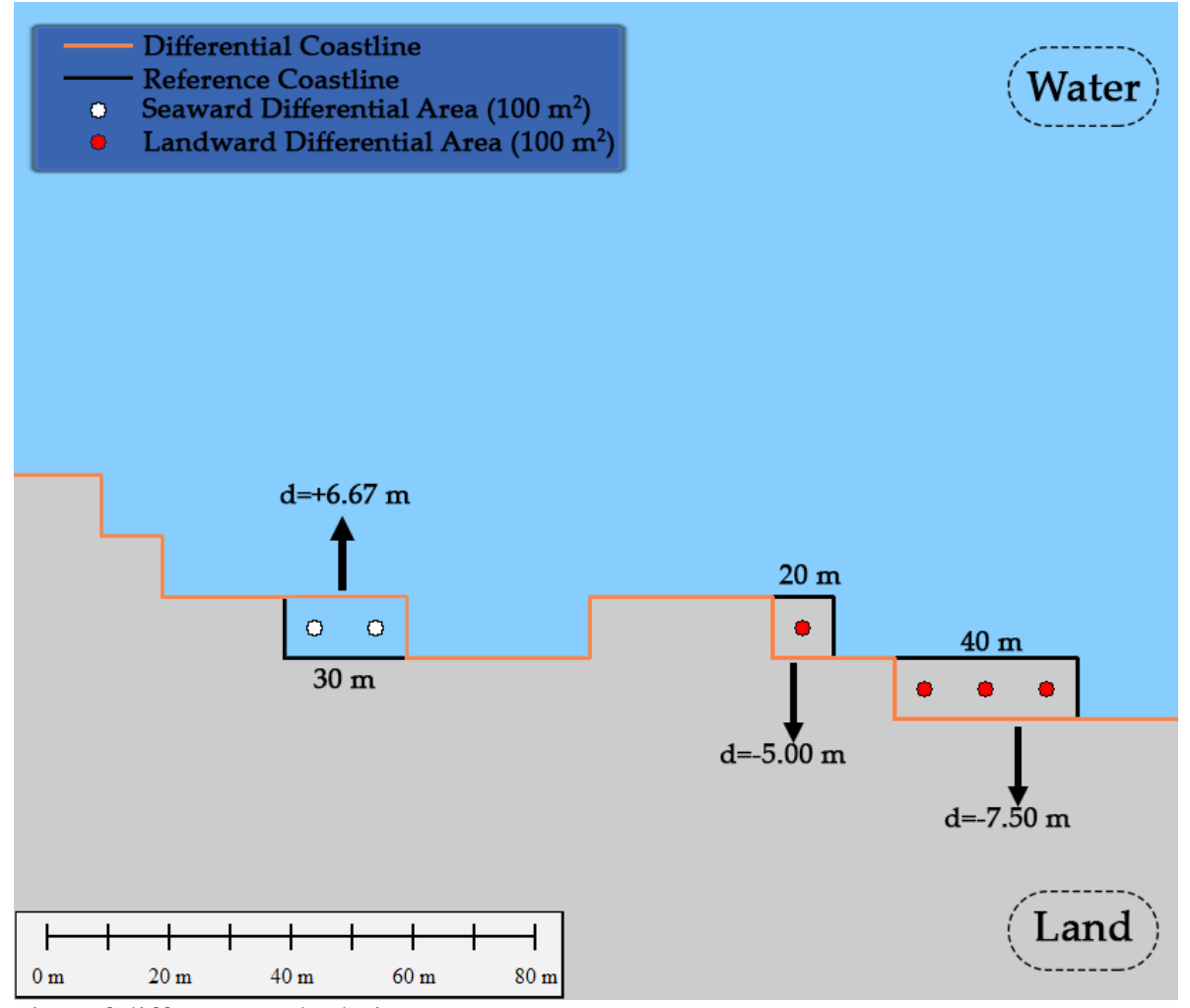

Fig. 3: Representation of difference calculation.

In order to calculate the difference per meter (d) (Equation 1) for a differential part, calculated area is divided by the reference coastline length $(\mathrm{L})$ of the differential part. Thus, amount of the difference $(|\mathrm{d}|)$, occurring at 1 meter in the differential parts is determined as a mean distance. If the deviation is seaward, the amount of difference is indicated as positive, if it is landward it is indicated as negative with a sign coefficient.

$$
\begin{aligned}
& d=s \frac{A}{L} \\
& s=\left\{\begin{array}{l}
+1 \rightarrow \text { deviation is seaward } \\
-1 \rightarrow \text { deviation is landwar }
\end{array}\right\}
\end{aligned}
$$

By repeating calculation of $\mathrm{d}$ for differential parts along the reference coastline a difference plot is occurred Fig. 4). By the help of this plot differential parts and differences are revealed along the reference coastline.

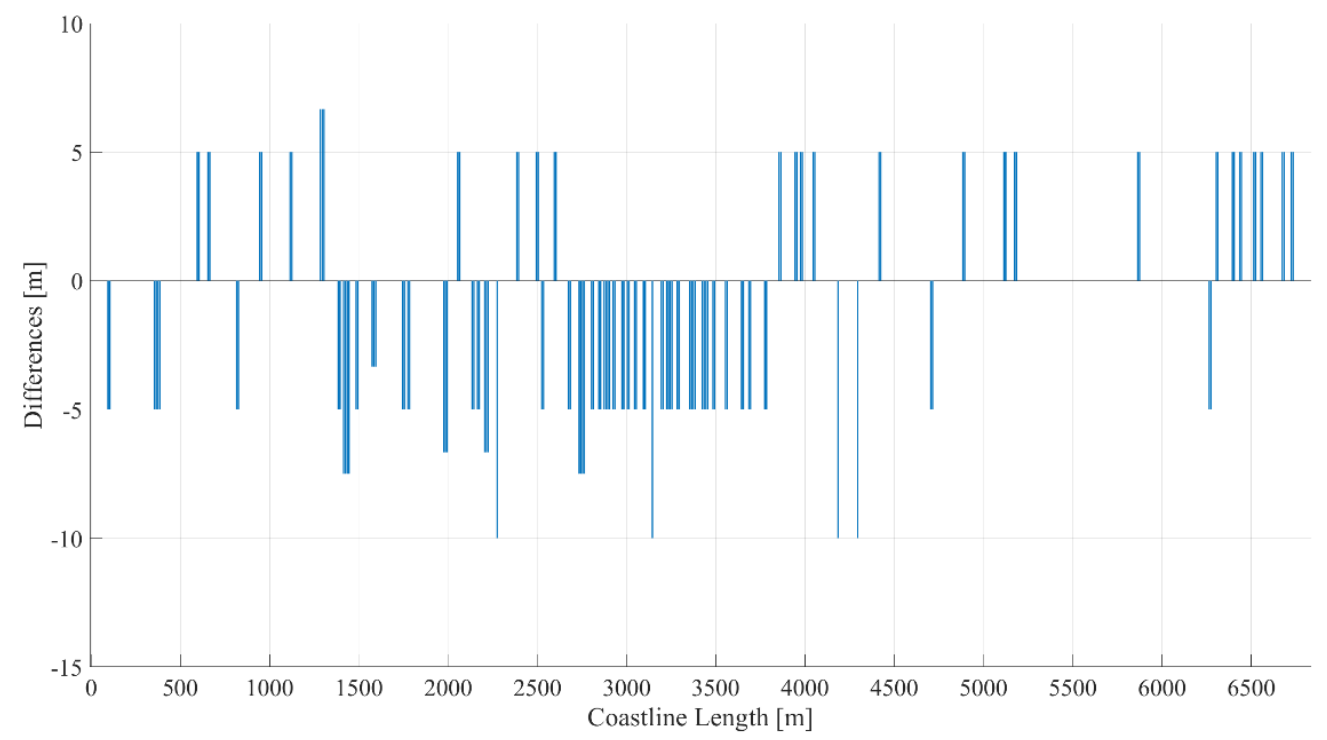

Fig. 4 Difference plot. 
To calculate the overall difference of two coastlines (D) over the number of differential parts (n) a similar formula to Root-mean-square deviation is applied with a difference of deviation coefficient ( $\rho$ ) (Equation 2).

$$
=\left(\frac{1}{\sum_{i=1}^{n} L_{i}} \sum_{i=1}^{n}\left(\left|d_{i}\right|\right)^{\rho} L_{i}\right)^{1 / \rho}
$$

D converges to absolute maximum difference (|dmax.|) while $\rho \rightarrow \infty$ and converges to absolute minimum difference (|dmin. $\mid)$ while $\rho \rightarrow-\infty$ with a sigmoidal curve. To find an optimum $\rho$ value to consider weights of large differences, $\rho$ is calculated by using variance to mean ratio as exponentially (Equation 3) (equation 4). While calculating variance value, $\mu$ refers to mean of absolute values of differences. To simply find the average of differences $\rho$ could be taken as 1 .

$$
\begin{gathered}
\sqrt{\frac{1}{\sum_{i=1}^{n} L_{i} \sum_{i=1}^{n}\left(\left|d_{i}\right|-\mu\right)^{2} L_{i}}} \\
\rho=\left\{\begin{array}{l}
\sigma \rightarrow \sigma \neq 0 \\
1 \rightarrow \sigma=0
\end{array}\right\}
\end{gathered}
$$

After d substituted in Equation 2 without sign coefficient since absolute values are considered, final formula to calculate overall differences (D) is obtained in equation 5.

$$
D=\left(\frac{1}{\sum_{i=1}^{n} L_{i}} \sum_{i=1}^{n}\left(A_{i}\right)^{\rho}\left(L_{i}\right)^{1-\rho}\right)^{1 / \rho}
$$

After method is applied to example case; $\rho$ and $\mathrm{D}$ values are calculated as $0.708 \mathrm{~m}$ and $5.047 \mathrm{~m}$ respectively.

\section{Results and Discussion:}

Coastline Difference Measurement method is designed to provide a fast and practical way to obtain distance differences between coastlines which belong to same area. The mathematics of the CDM method provides a solid foundation for the processing and calculation of real-world differences, such as shoreline lengthcoastline. Due to the mathematics concept of the CDM method, it is seen that the level of accuracy is comparatively better than the conventional methods. In the light of this assessment, using the CDM method as an alternative for qualified coastline extraction has practical benefits.

Main advantages of this method are:

- Calculates overall differences by decreasing the effect of the coastline shape and applicable wider range of complex shaped coastlines.

- Decreasing time of pre-processing.

- Providing repeatable results from multiple users while measuring differentiations from reference coastlines.

- Providing opportunity to make more comparisons in the same amount of time to obtain statistical significances of the coastline extraction methods for researchers.

- Helps the automatizations of coastline change detection processes by decreasing the supervising requirements.

- Thresholding, edge detection and effective contour fitting improved the accuracy of the removed coastline.

Limitations of the method are:

- Since the intersections required to calculate differences, detailed results may not occurs along the reference coastline if there is low number of intersection points.

- Different algorithms or any other technique should be applied to generate a more accurate coastal surface classification map for mapping accurate shorelines in various coastal zones.

- As the worst case, method just detects 2 intersection points (start and end points) and calculates overall difference as dividing differential are by reference coastline length.

- Ground truths acquired by the traditional surveying method could be used for determining accuracies of the generated coastline.

\section{References}

Buitinck, L.; Louppe, G.; Blondel, M.; Pedregosa, F.; Mueller, A.; Grisel, O.; Niculae, V.; Prettenhofer, P.; Gramfort, A.; Grobler, J.; Layton, R.; VanderPlas, J.; Joly, A.; Holt, B.; Varoquaux, G. API design for machine learning software: experiences from the scikit-learn project. ECML PKDD Workshop: Languages for Data Mining and Machine Learning, 2013, pp. 108-122.

Gazioğlu C, Yücel Y Z, Burak S., Okuş, E. and Alpar, B. (1997). Coastline change and inadequate management between Kilyos and Karaburun shoreline. Turkish Journal of Marine Sciences, 3(2): 111-122.

Kavzoğlu, T., Cölkesen, I. (2009). A kernel functions analysis for support vector machines for land cover classification. International Journal of Applied Earth Observation and Geoinformation, 11, 352-359. 
Kaya, H. (2010). The Role of Local Governments in Integrated Coastal Areas Management. IU PhD thesis, Istanbul.

Nassar, K., Mahmod, W. E., Fath, H., Masria, A., Nadaoka, K., \& Negm, A. (2019). Shoreline change detection using DSAS technique: Case of North Sinai coast, Egypt. Marine Georesources \& Geotechnology, 37(1), 81-95.

Paravolidakis, V., Ragia, L., Mairogiorgou, K., Zerkavis, ME. (2018). Automatic Coastline Extraction Using Edge Detection and Optimization Procedures, Geosciences 8, 407-425.

Pedregosa, F.; Varoquaux, G.; Gramfort, A.; Michel, V.; Thirion, B.; Grisel, O.; Blondel, M.; Prettenhofer, P.; Weiss, R.; Dubourg, V.; Vanderplas, J.; Passos, A.; Cournapeau, D.; Brucher, M.; Perrot, M.; Duchesnay, E. (2011). Scikit-learn: Machine Learning in Python. Journal of Machine Learning Research, 12, 2825 2830.

Python Software Foundation. Python Language Reference, version 3.8. Available at http://www.python.org

Simav, Ö., Şeker, DZ., Gazioğlu, C. (2013). Coastal inundation due to sea level rise and extreme sea state and its potential impacts: Çukurova Delta case, Turkish Journal of Earth Sciences 22 (4), 671-680.

Wicaksono, A., Wicaksono, P., Khakhim, N., Farda, N. M., Marfai, M. A. (2019). Semi-automatic shoreline extraction using water index transformation on Landsat 8 OLI imagery in Jepara Regency. Sixth International Symposium on LAPAN-IPB Satellite, 11372, 113721I.

Yu, L., Porwal, A., Holden, EJ., Dentith, MC. (2012). Towards automatic lithological classification from remote sensing data using support vector machines. Computers \& Geosciences, 45, 229-239.

Yulianto, F., Suwarsono, S., Maulana, T., Khomarudin, M. R. (2019). The dynamics of shoreline change analysis based on the integration of remote sensing and geographic information system (GIS) techniques in Pekalongan coastal area, Central Java, Indonesia. Journal of Degraded and Mining Lands Management, 6(3), 1789.

Zhang, T., Yang, X., Hu, S., Su, F. (2013). Extraction of Coastline in Aquaculture Coast from Multispectral Remote Sensing Images: Object-Based Region Growing Integrating Edge Detection, Remote Sens. 5, 4470-4487.

Zollini, S., Alicandro, M., Cuevas-González, M., Baiocchi, V., Dominici, D., Buscema, P. M. (2020). Shoreline Extraction Based on an Active Connection Matrix (ACM) Image Enhancement Strategy. Journal of Marine Science and Engineering, 8(1), 9. 